\title{
Preparation of heterogeneous Fenton-Type nano catalysts and their application to methylene blue degradation
}

\author{
Co Thanh Thien ${ }^{1,2,{ }^{*}}$, Le Dinh Khoi ${ }^{1}$, Doan Thi Nhu Thuy ${ }^{1}$, Le Van De ${ }^{1}$
}

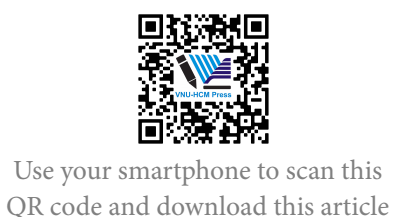

${ }^{1}$ University of Science, Ho Chi Minh City, Vietnam

${ }^{2}$ Vietnam National University, Ho Chi Minh City, Vietnam

Correspondence

Co Thanh Thien, University of Science, Ho Chi Minh City, Vietnam

Vietnam National University, Ho Chi Minh City, Vietnam

Email: ctthien@hcmus.edu.vn

History

- Received: 2020-08-28

- Accepted: 2020-11-02

- Published: 2020-12-02

DOI : 10.32508/stdj.v23i4.2451

\section{Check for updates}

\section{Copyright}

(c) VNU-HCM Press. This is an openaccess article distributed under the terms of the Creative Commons Attribution 4.0 International license.

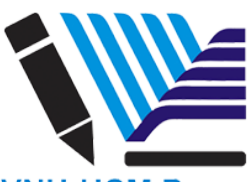

VNU-HCM Press

\begin{abstract}
Introduction: Iron-based nanocatalysts are known as a new generation heterogeneous Fenton catalyst, replacing the traditional Fenton catalyst system which has many disadvantages in experimental processes and industrial applications. In this study, we focused on the preparation of iron nanoparticles and their use when embedded in traditional supports, as well as tested their catalytic activity by modified Fenton-type oxidation of methylene blue (MB) substrate. Method: Scanning Electron Microscope (SEM), Transmission Electron Microscopy (TEM), X-ray diffraction (XRD) and UV-vis were used for physio-chemical characterization of the catalysts. Results: Iron nanoparticles were obtained in the reduction of iron salt by sodium borohydride $\left(\mathrm{NaBH}_{4}\right)$, with particle size in the range of 4-5 nm. Fe-X ( $\mathrm{X}$ represents $\mathrm{C}$, Bentonite, $\mathrm{Al}_{2} \mathrm{O}_{3}$, or $\mathrm{ZnO}$ ) was synthesized in high yield and applied to the Fenton oxidation of MB; approximately $99 \%$ conversion was observed in the case of Fe-C. Conclusion: Supported iron nanoparticles are active catalysts for the oxidation of $\mathrm{MB}$; however, there are limitations if $\mathrm{pH}$ is above 3.

Key words: Fenton, nanocatalyst, iron catalyst, oxidation, water treatment
\end{abstract}

\section{INTRODUCTION}

In recent years, wastewater containing synthetic dyes have garnered increased attention due to factors such as continuous discharge, low toxicity and biodegradation $^{1,2}$. Specifically, the oxidation of methylene blue (MB) and basic dyes of thiazine are receiving greater interest. Therefore, treatment by Fenton method has been attracting many researchers ${ }^{3-6}$.

Iron-based nanocatalysts are known as a new generation heterogeneous Fenton catalyst which can replace the traditional Fenton catalyst system that has many disadvantages in experimental processes as well as in industrial applications ${ }^{7}$. Both heterogenous and homogeneous Fenton catalysts show similar activity for the same amount of catalyst used. However, in the case of traditional Fenton catalysts, there is a need for a considerable amount of chemicals and manpower to remove the mixture containing the iron catalysts ${ }^{8}$. Therefore, in order to improve the Fenton process, a number of reports have used supported iron catalysts for applications in drug sciences ${ }^{9}$, treatment of heavy metal pollution ${ }^{10}$, chemical catalysis ${ }^{11}$, and industrial textile and dyes ${ }^{12}$.

Moreover, due to the reduction of metal, ethylene gly$\mathrm{col}$ (EG) reduction is a common process for the preparation of metal nanoparticles. In particular, with iron reduction, high temperature or microwave irradiation is usually required to improve the reduction performance ${ }^{13,14}$. Sodium borohydride $\left(\mathrm{NaBH}_{4}\right)$ is considered as a force reducing agent which can reduce ionic precursors at room temperature; a disadvantage of the $\mathrm{NaBH}_{4}$ process, however, is the formation of irregular particle size ${ }^{15}$. Consequently, the combination of the $\mathrm{EG}$ and $\mathrm{NaBH}_{4}$ processes can yield better reduction in the preparation of the nanoparticles.

In this study, we describe the preparation of iron nanoparticles and their use as a new catalyst and impregnated into traditional supports, as well as evaluate their catalytic activities by modified Fenton-type oxidation of MB substrate.

\section{MATERIALS - METHODS}

\section{Materials}

Unless otherwise noted, all procedures were carried out in air. Reagent grade iron(II) sulfate heptahydrate 99.5\% $\left(\mathrm{FeSO}_{4} .7 \mathrm{H}_{2} \mathrm{O}\right)$, ethylene glycol 99.5\% (EG), methylene blue (MB), and sodium borohydride $98 \%$ $\left(\mathrm{NaBH}_{4}\right)$ were purchased from Merck (Germany). Aluminum oxide $\left(\mathrm{Al}_{2} \mathrm{O}_{3}\right)$, zinc oxide $(\mathrm{ZnO})$, hydrogen peroxide $\left(\mathrm{H}_{2} \mathrm{O}_{2}\right)$, and polyvinyl pyrrolidone- $\mathrm{K} 30$ (PVP) were purchased from various Chinese suppliers (Xilong, China). Binh Thuan bentonite (Bent) and activated carbon were purchased from local suppliers (Binh Thuan, Vietnam). Absolute ethanol and methanol were supplied by CHEMSOL (Ho Chi Minh city, Vietnam). 


\section{Characterization}

The morphology of iron catalysts was examined by scanning electron microscope (SEM) (Hitachi S4800, Japan). Transmission Electron Microscopy (TEM) images was collected using FEI Tecnai G2 F20 (University of Technology, Ho Chi Minh city). The Xray diffraction (XRD) data of all samples were collected in a Philip X-Ray (Vietnam Petroleum Institute, Ho Chi Minh city) with $\mathrm{Cu} \mathrm{K}_{\alpha}$ radiation running at $35 \mathrm{kV} / 30 \mathrm{~mA}$ in the $2 \theta$ range $5^{\circ}-75^{\circ}$ with a step size of $0.2^{\circ} / \mathrm{min}$. Nitrogen adsorption-desorption isotherms were collected at $77 \mathrm{~K}$ using BrunauerEmmett-Teller calculation (BET, AUTOSORB-1C Quantachrome); all samples were degassed at 100 ${ }^{\circ} \mathrm{C}$ and $10^{-6} \mathrm{~Pa}$. UV spectras were recorded on Agilent Cary 60 UV-Vis (Applied Physical Chemistry Laboratory of VNUHCM-University of Science, Ho Chi Minh city). Atomic Absorption pectroscopy (AAS) was analysed on Agilent 240AAS (Laboratory of Analysis-University of Science, Ho Chi Minh city). All the catalytic test were performed in a Multireactors Carousel 12 lus system (Laboratory of CatalysisUniversity of Science, Ho chi Minh city).

\section{Catalyst preparation}

To a two-necked roundbottom flask, $\mathrm{FeSO}_{4} .7 \mathrm{H}_{2} \mathrm{O}$ $(0.5 \mathrm{~g}, 1.8 \mathrm{mmol})$ and $50 \mathrm{~mL}$ of deionized (DI) water were added. After stirring for $15 \mathrm{~min}, 25 \mathrm{~mL}$ of absolute ethanol and $1 \mathrm{~g}$ of PVP were added into the mixture. In another flask, a mixture of EG $(2.0 \mathrm{~mL})$ and $\mathrm{NaBH}_{4}(0.1 \mathrm{~g}, 2.7 \mathrm{mmol})$ in $50 \mathrm{~mL}$ of DI water were prepared. Then, the reducing agent solution was added in a dropwise fashion to the mixture of iron salt, which was stirred until the solution appeared black. The iron nanoparticles were then loaded on the supports (X), such as $\mathrm{Al}_{2} \mathrm{O}_{3}$, bentonite, $\mathrm{ZnO}$ or activated carbon, under vacuum at room temperature. The process was repeated several times to make sure all the iron nanoparticles were loaded onto $\mathrm{X}$.

\section{Catalyst evaluation}

In this study, the activity of the catalyst was investigated via the degradation of MB under aqueous solution. The catalytic evaluation of $\mathrm{Fe}-\mathrm{X}$ was carried out in a $20 \mathrm{~mL}$ multireactor with stirring at room temperature. In this process, $5.0 \mathrm{~mol} \%$ of $\mathrm{Fe}-\mathrm{X}$ was used in the $\mathrm{MB}$ aqueous solution of $40 \mathrm{mg} / \mathrm{L}(10 \mathrm{~mL})$, and $1.0 \mathrm{~mL}$ of $30 \%$ hydrogen peroxide solution in water. The influence of $\mathrm{pH}$ on the process (at $\mathrm{pH} 3.0,5.0$, and 7.0) was observed by dosing hydrochloric acid. The concentration changes of MB were recorded by the colorimetric method at the maximum absorbance of $664 \mathrm{~nm}$. Reproducibility was checked by repeating the measurement several times and was found to be within acceptable limits.

\section{RESULTS}

Iron nanoparticles were prepared by the reduction of $\mathrm{FeSO}_{4} .7 \mathrm{H}_{2} \mathrm{O}$ using a combination of EG and $\mathrm{NaBH}_{4}$ as reducing agent. The original blue solution turned dark when $\mathrm{Fe}^{0}$ nanoparticles formed. The solution was then subjected to UV-Vis measurement.

Figure 1 show the UV-Vis spectra of the iron nanoparticles prepared at room temperature. The absorption range of 300-320 $\mathrm{nm}$ was assigned for the absorption peaks of $\mathrm{Fe}^{2+}$ and $\mathrm{Fe}^{3+}$ ions. The solution of PVP did not absorb at the UV zone.

In addition, the solution of iron nanoparticles were further analyzed by TEM technique. TEM images were taken at $20 \mathrm{~nm}, 50 \mathrm{~nm}$, and $100 \mathrm{~nm}$. As illustrated in Figure 3, the average size of the iron nanoparticles was in the range of 4-5 $\mathrm{nm}$.

According to AAS analysis, the concentration of supported iron nanoparticles as $\mathrm{Fe}-\mathrm{Al}_{2} \mathrm{O}_{3}, \mathrm{Fe}-\mathrm{ZnO}, \mathrm{Fe}$ Bent, and Fe-C were recorded at 14.20, 13.95, 12.00, and $10.77 \mathrm{wt} \%$, respectively.

The surface morphology of Fe-X was characterized by SEM. As illustrated in Figure 4, the surface of Fe$\mathrm{Al}_{2} \mathrm{O}_{3}$ (A) showed uniform particles, with a number of spherical shape formed between the pores. Likewise, the surface of Fe-Bentonite (D) showed a similar morphology; both samples had similar specific surface area. In contrast, in the case of Fe-C (B), from the thickness of the slit-shaped pores which formed around the surface, it appeared that most of iron nanoparticles had not successfully attached to the activated carbon. Unfortunately, in the case of Fe-Bent (C), the surface was smooth, with a few pores, and with big cubic shapes covering the surface of the catalyst. It is worth noting that during the loading process, the spherical shape could be destroyed.

Moreover, Table 1 indicates that the surface area of $\mathrm{Fe}-\mathrm{C}$ was the highest compared to the other samples. In contrast, the surface of $\mathrm{Fe}-\mathrm{ZnO}$ and Fe-Bent was smooth and had thin pores; thus the surface area was very low (approximately $28-42 \mathrm{~m}^{2} \cdot \mathrm{g}^{-1}$ ). The supported iron nanoparticles did not have much of an effect on the surface area of the supports.

In order to evaluate the oxidation activity of the catalysts, $5.0 \mathrm{~mol} \%$ of the Fe-X catalysts was used to oxidate MB solution in the presence of hydrogen peroxide. All experiments and results are summarized in Figure 5.

$$
\begin{aligned}
& {[\mathrm{MB}] \stackrel{[\mathrm{Fe}-\mathrm{X}]}{\longrightarrow}[\text { Degradation organics }]} \\
& +\mathrm{CO}_{2}+\mathrm{H}_{2} \mathrm{O}
\end{aligned}
$$




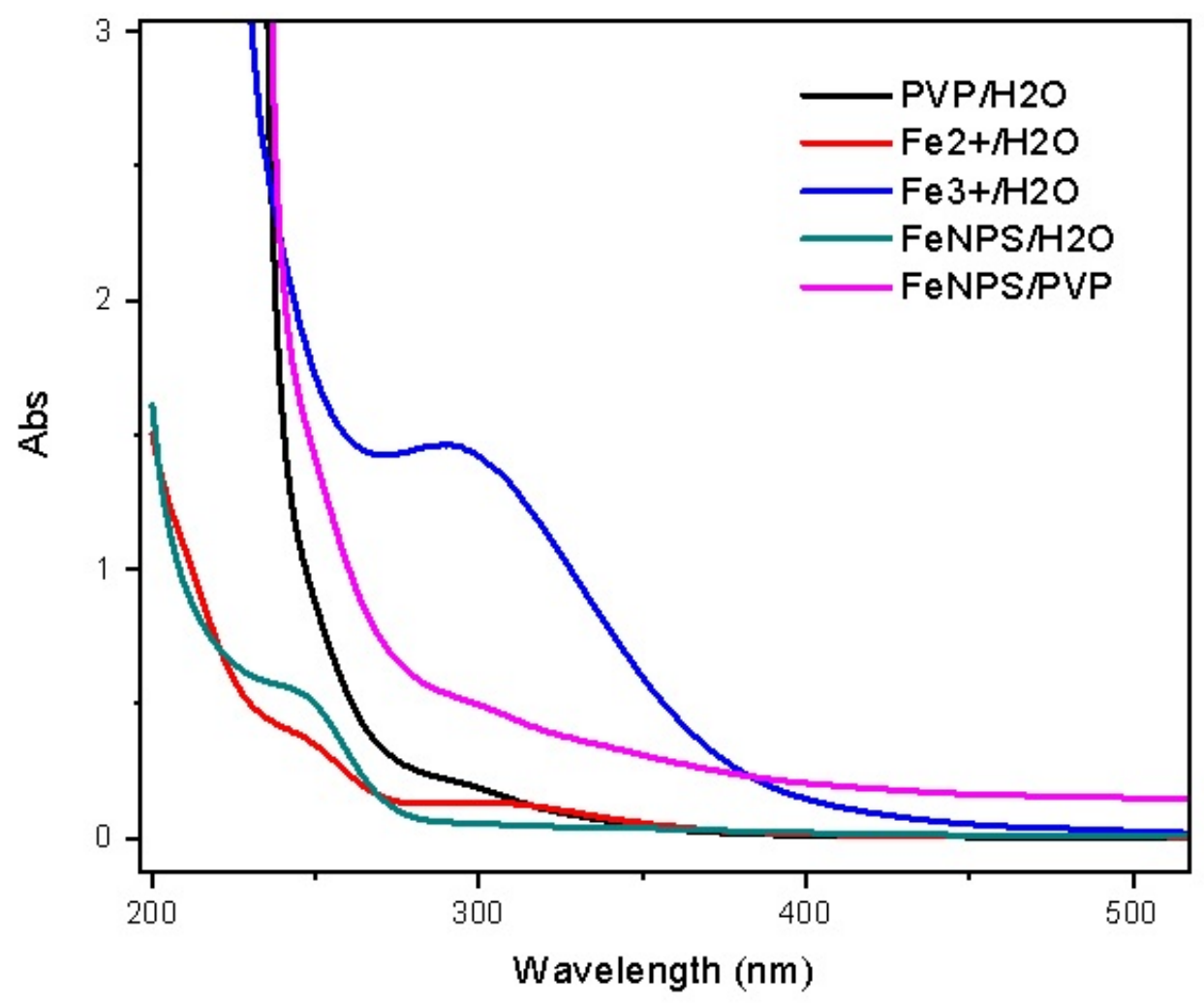

Figure 1: UV-vis absorbance spectra of the solution of iron nanoparticles which were reduced by a combination of EG and $\mathrm{NaBH}_{4}$ at room temperature.

\section{DISCUSSION}

According to $\mathrm{H}$. Chen ${ }^{16}$, the characteristic spectra of iron nanoparticles are at two peaks, $\lambda=216 \mathrm{~nm}$ and $268 \mathrm{~nm}$. In Figure 1, an absorption peak at 268 $\mathrm{nm}$ was observed in the solution of iron nanoparticles, even if it was slightly smooth and seemed to be obscured. In addition, there was no absorption peaks of the $\mathrm{Fe}^{2+}$ and $\mathrm{Fe}^{3+}$ ions in this solution. This demonstrates that almost all $\mathrm{Fe}^{2+}$ ion were successfully reduced to $\mathrm{Fe}^{0}$ nanoparticles. This was also confirmed by XRD pattern in Figure 2, in which four cases showed the characteristic peak at $2 \theta$ angles of $44.9^{\circ}$ (assigned for metallic iron), even though the peaks were rather weak due to the low concentration of iron nanoparticles in the samples.

As observed in Figure 3, the shape and size of the iron nanoparticles were determined to be spherical and in the range of 4-5 $\mathrm{nm}$. These observations could be explained by the fact that the iron nanoparticles were protected and dispersed by the PVP molecules. Furthermore, the PVP molecules may have prevented the

\section{Table 1: Specific surface areas of catalysts}

\begin{tabular}{cc}
\hline Catalysts & $\mathbf{S}_{B E T}\left(\mathbf{m}^{2} \cdot \mathbf{g}^{-1}\right)$ \\
$\mathrm{Fe}^{-\mathrm{Al}_{2} \mathrm{O}_{3}}$ & 69.98 \\
$\mathrm{Fe}-\mathrm{C}$ & 224.69 \\
$\mathrm{Fe}-\mathrm{ZnO}$ & 27.78 \\
Fe-Bentonite & 41.81 \\
\hline
\end{tabular}

agglutination and deposition of the iron nanoparticles.

The catalytic oxidation exhibited an excellent decomposition of MB, as shown in Figure 5. All the ironsupported samples exhibited high activities, in particular Fe-C, which had the highest surface area and showed the best conversion (up to $99.7 \%$ in the case of $\mathrm{pH} 3$ ). On the other hand, the influence of $\mathrm{pH}$ was also observed. For example, the conversion of $\mathrm{MB}$ was decreased when $\mathrm{pH}$ was increased to neutral. In the case of the Fe- $\mathrm{ZnO}$ catalyst, the conversion was decreased to $84.8 \%$ at $\mathrm{pH} 7$, whereas it increased to $90.2 \%$ and $97.9 \%$ conversion at $\mathrm{pH} 5$ and 


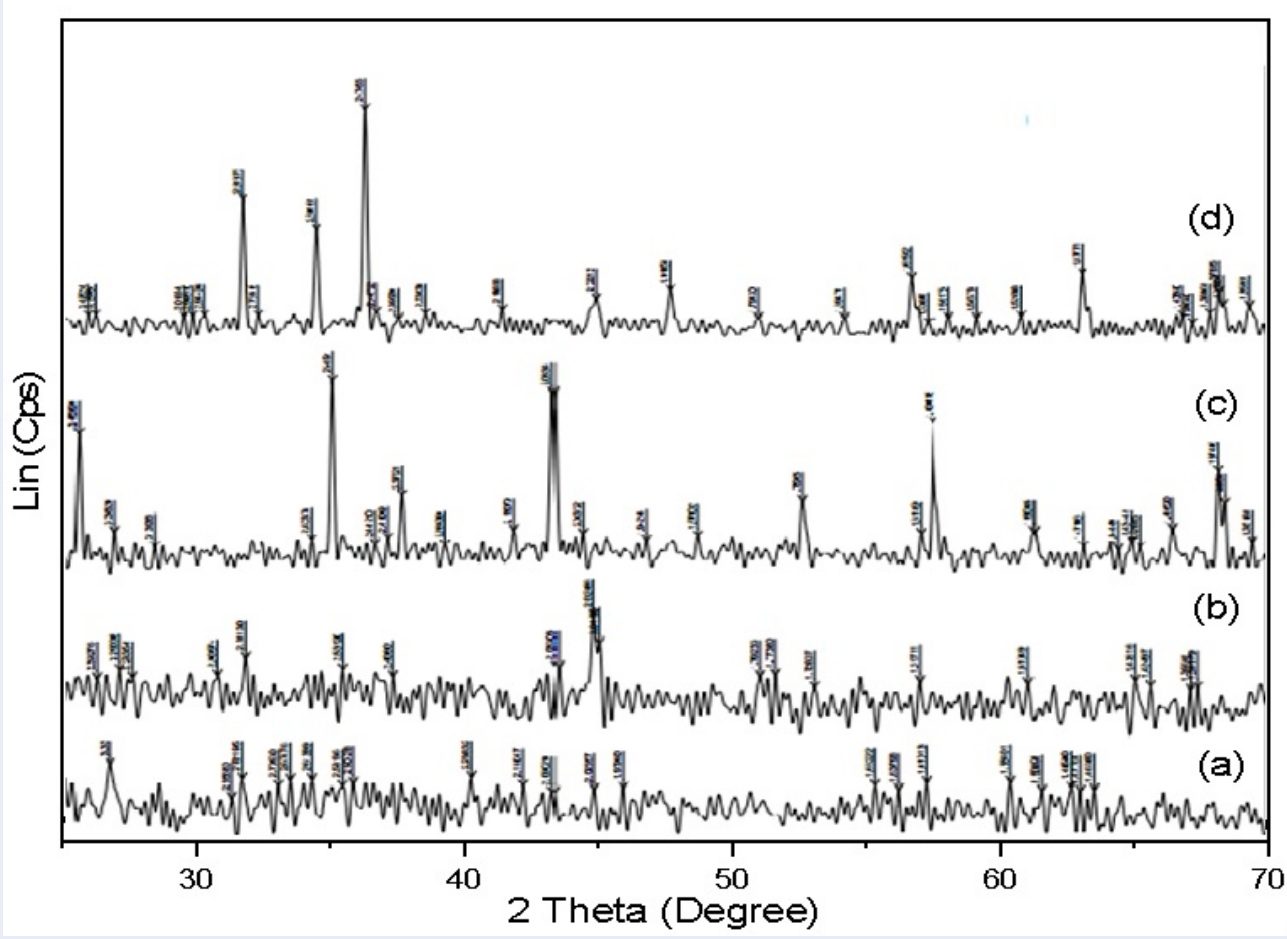

Figure 2: XRD patterns of: A) Fe-Bentonite, $\mathrm{B}$ )Fe-C, C) $\mathrm{Fe}-\mathrm{Al}_{2} \mathrm{O}_{3}$, and D) $\mathrm{Fe}-\mathrm{ZnO}$; all were dried at $60^{\circ} \mathrm{C}$ under vacuum for $8 h$.

$\mathrm{pH} 3$, respectively. It could be explained that in acidic environment, iron nanoparticles are more easily oxidized to iron ions, which play an important role in the Fenton-type heterogenous catalysis ${ }^{17}$. Likewise, in the case of other samples, the MB conversion decreased to $89.2 \%$ and $78.9 \%$ at $\mathrm{pH} 7$, as was the case with $\mathrm{Fe}-\mathrm{C}$ and Fe-Bent catalysts, respectively. However, it was still lower than that at $\mathrm{pH} 5$ for the conversion of $95.6 \%$ (Fe-C) and $86.7 \%$ (Fe-Bent). It is clear that in the case of $\mathrm{pH} \mathrm{5,} \mathrm{a} \mathrm{moderate} \mathrm{conversion} \mathrm{were}$ obtained. In order to propose the specific mechanism (Equation (1)), we may need to further investigate the kinetics reaction. The present catalysts- with their stability and activities- are potentially the most promising candidate for application in water pollution treatment.

\section{CONCLUSION}

This study prepared and characterized $\mathrm{Fe}-\mathrm{X}$ particles ( $\mathrm{X}=\mathrm{C}$, Bentonite, $\mathrm{Al}_{2} \mathrm{O}_{3}$, or $\mathrm{ZnO}$ ) as catalysts. All the physio-chemical charaterization of the catalysts were evaluated in detail. All the results corroborated with the loading process. Indeed, XRD and TEM analyses indicated that iron was incoporated as $\mathrm{Fe}^{0}$ inside $\mathrm{X}$. Moreover, the catalytic test indicated that almost all the supported iron nanoparticles exhibited high catalytic activities, especially at $\mathrm{pH} 3$ where the conversion of $\mathrm{MB}$ reached $99.7 \%$ with the $\mathrm{Fe}-\mathrm{C}$ catalyst.

\section{ABBREVIATIONS}

Bent: bentonites

DI: deionized

EG: ethylene glycol

MB: methylene blue

PVP: polyvinyl pyrrolidone-K30

Zeolit: zeolites

\section{COMPETING INTERESTS}

The authors declare that there are no conflicts of interest regarding the publication of this paper.

\section{AUTHOR'S CONTRIBUTION}

Co Thanh Thien has conceived of the present idea, carried out and written the manuscript. Le Dinh Khoi, Le Van De and Doan Thi Nhu Thuy carried out the experiments and analyzed all the samples.

\section{ACKNOWLEDGMENT}

This research is funded by Vietnam National University Ho Chi Minh City (VNU-HCM) under grant number C2019-18-13. 

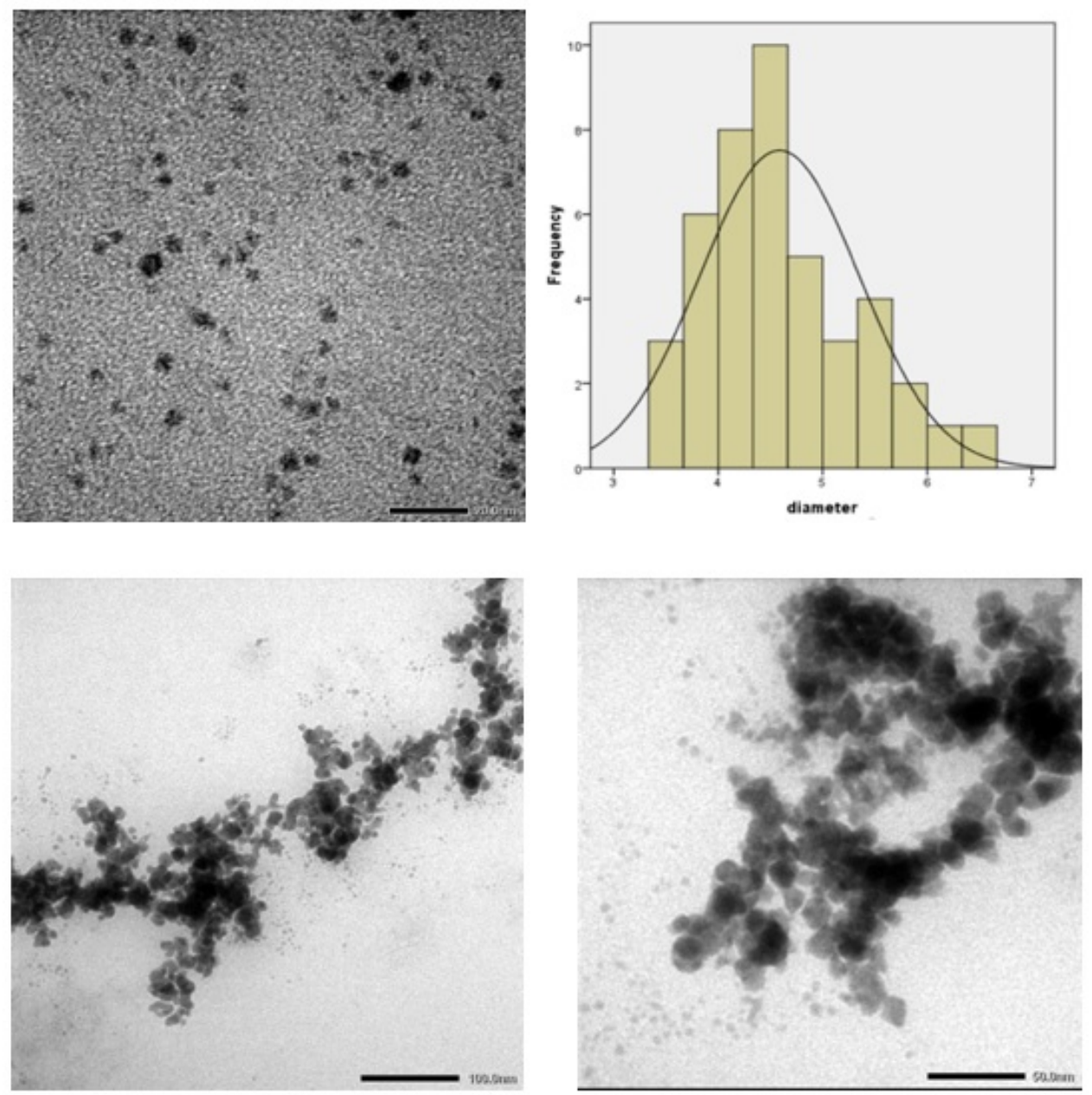

Figure 3: TEM images of Fe nanoparticles taken at 20, 50, and $100 \mathrm{~nm}$.

\section{REFERENCES}

1. Romero NA, Nicewicz DA. Organic Photoredox Catalysis. Chem Rev. 2016;116(17):10075-10166. PMID: 27285582 Available from: https://doi.org/10.1021/acs.chemrev.6b00057.

2. Hiền TT, Anh LH, Thiện PH, Thành NĐ. Preparation of activated carbons from coffee husks by hydrothermal carbonization method and application in Methylene Blue dye removal. Vietnam J Catal Adsorpt. 2019;8(4):1-9. Available from: http://chemeng.hust.edu.vn/jca/images/Paper/4-2019/42019-p001-009.pdf.

3. Kuan CC, Chang SY, Schroeder SLM. Fenton-like oxidation of 4-chlorophenol: Homogeneous or heterogeneous. Ind Eng Chem Res. 2015;54(33):8122-8129. Available from: https:// doi.org/10.1021/acs.iecr.5b02378.

4. Hoan NTV, Minh NN, Nhi TTK, Van Thang N, Tuan VA, Nguyen VT, et al. TiO2/Diazonium/graphene oxide composites: Synthesis and visible-light-driven photocatalytic degradation of methylene blue. J Nanomater. 2020;2020:1-15. Available from: https://doi.org/10.1155/2020/4350125.

5. Quan GC, Le TK. Preparation of magnetic photo-Fenton catalysts based on $\mathrm{CuFe} 2 \mathrm{O} 4$ by the starchassisted sol-gel method. Sci. Technol Dev J - Nat Sci. 2017;5:102-109. Available from: https://doi.org/10.32508/stdjns.vliT5.541.

6. Linh HN, Ho HTN. Bio-Electro-Fenton: a novel method for treating leachate in Da Phuoc Landfill, Vietnam. Sci Technol Dev J. 2020;23(1):461-469. Available from: https://doi.org/10. 32508/stdj.v23i1.1736.

7. Saufi H, El Alouani M, Alehyen S, El Achouri M, Aride J, Taibi M. Photocatalytic Degradation of Methylene Blue from Aqueous Medium onto Perlite-Based Geopolymer. Int J Chem Eng. 2020;2020:1-7. Available from: https://doi.org/10.1155/2020/ 9498349.

8. Phan CN, Phan TTN, Pham TH. Heterogeneous Fenton-like LFO catalyst for the degradation of organic pollutant in wastewater. Vietnam J Catal Adsorpt. 2019;8(4):110-115. Available from: http://chemeng.hust.edu.vn/jca/images/Paper/4-2019/42019-p110-115.pdf.

9. Ayodele OB, Lim JK, Hameed BH. Pillared montmorillonite supported ferric oxalate as heterogeneous photo-Fenton catalyst for degradation of amoxicillin. Appl Catal A Gen. 2012;413(414). Available from: https://doi.org/10.1016/j. apcata.2011.11.023.

10. Li H, Zhang H, Long J, Zhang P, Chen Y. Combined Fenton process and sulfide precipitation for removal of heavy metals from industrial wastewater: Bench and pilot scale studies focusing on in-depth thallium removal. Front Environ Sci Eng. 2019;13(4):1-12. Available from: https://doi.org/10.1007/ s11783-019-1130-7. 


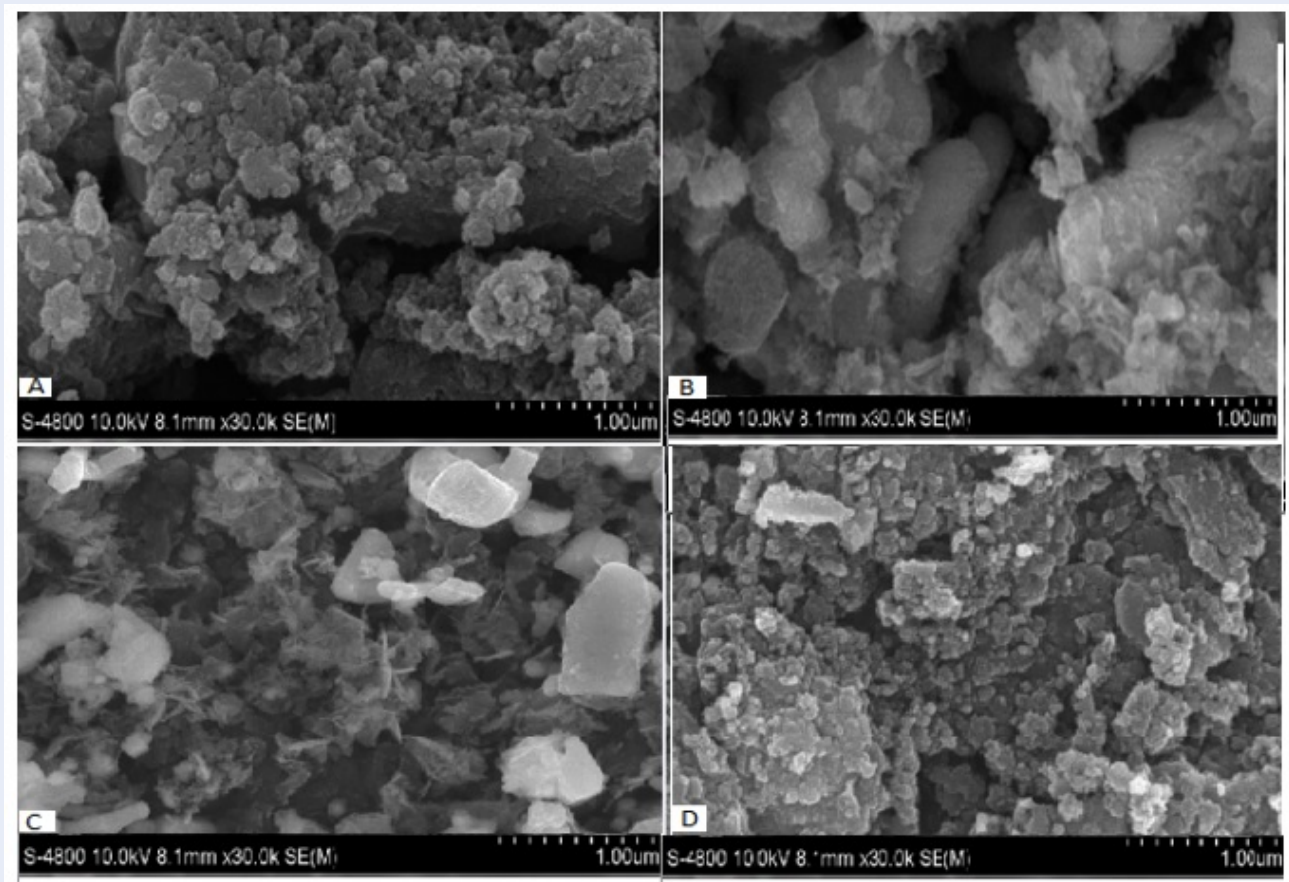

Figure 4: SEM images of: A) Fe-Al $\left.\left.{ }_{2} \mathrm{O}_{3}, \mathrm{~B}\right) \mathrm{Fe}-\mathrm{C}, \mathrm{C}\right) \mathrm{Fe}-\mathrm{ZnO}$, and D) Fe-Bent. The images were taken at $1.0 \mu \mathrm{m}$.

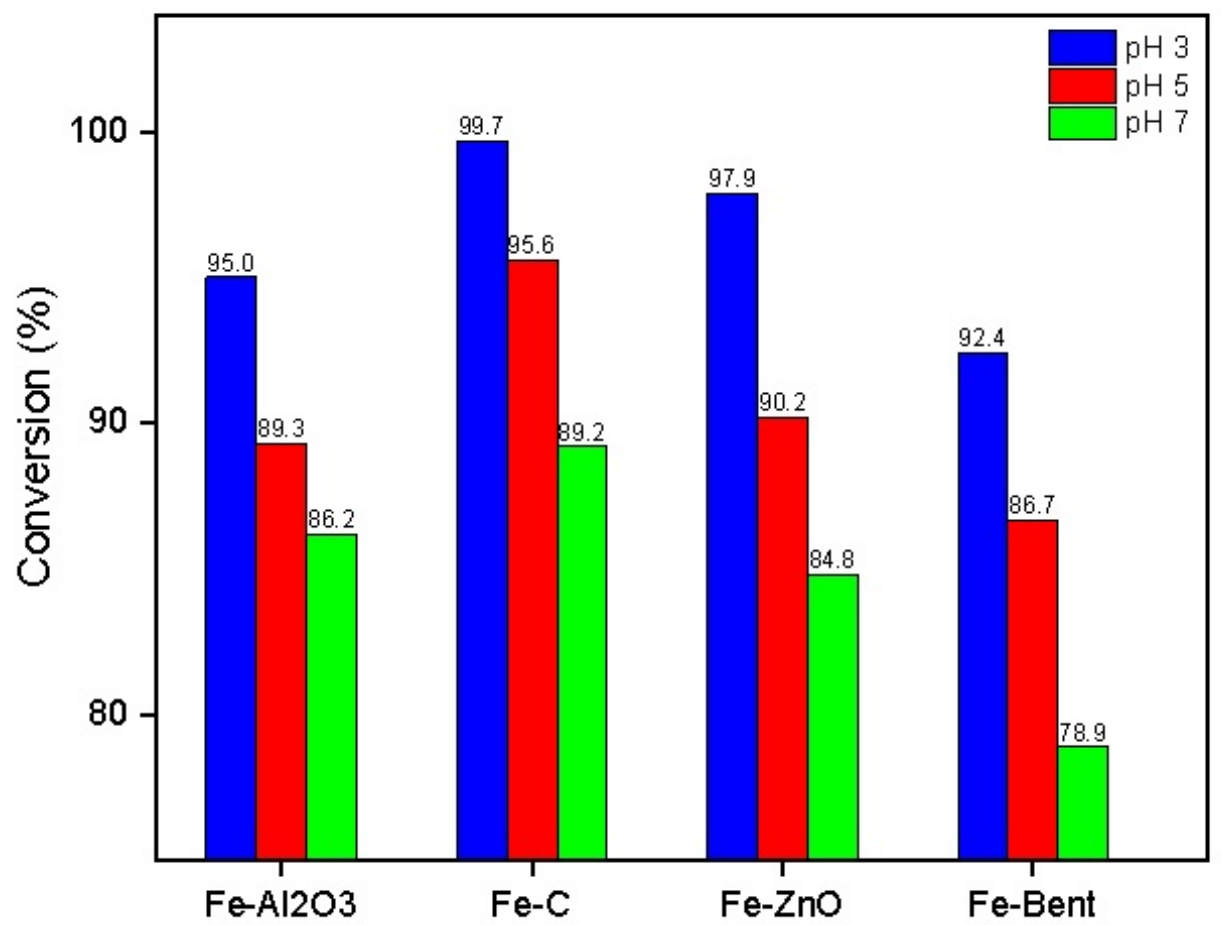

Figure 5: Catalytic activities of Fe-X over MB conversion. Reaction condition: 5 mol\% of catalyst at pH 3, pH 5 , and $\mathrm{pH} 7 ;[\mathrm{MB}]=\mathbf{4 0} \mathrm{mg} / \mathrm{L}$; reaction time was $60 \mathrm{~min}$. 
11. Fu N, Ren XC, Wan JX. Preparation of ag-coated SiO2@TiO2 core-shell nanocomposites and their photocatalytic applications towards phenol and methylene blue degradation. J Nanomater. 2019;2019:1-8. Available from: https://doi.org/10. $1155 / 2019 / 8175803$.

12. Rodríguez A, Ovejero G, Sotelo JL, Mestanza M, García J. Heterogeneous fenton catalyst supports screening for mono azo dye degradation in contaminated wastewaters. Ind Eng Chem Res. 2010;49(2):498-505. Available from: https://doi.org/10. 1021/ie901212m.

13. Song P, Liu L, Wang AJ, Zhang X, Zhou SY, Feng JJ. One-pot synthesis of platinum-palladium-cobalt alloyed nanoflowers with enhanced electrocatalytic activity for ethylene glycol oxidation. Electrochim Acta. 2015;164:323-329. Available from: https://doi.org/10.1016/j.electacta.2015.02.229.

14. Mathiyarasu J, Phani KLN. Carbon-Supported PalladiumCobalt-Noble Metal (Au, Ag, Pt) Nanocatalysts as Methanol Tolerant Oxygen-Reduction Cathode Materials in DMFCs. J
Electrochem Soc. 2007;154(11):1100-1105. Available from: https://doi.org/10.1149/1.2772417.

15. Kim P, Joo JB, Kim W, Kim J, Song IK, Yi J. NaBH4-assisted ethylene glycol reduction for preparation of carbon-supported $\mathrm{Pt}$ catalyst for methanol electro-oxidation. J Power Sources. 2006;160(2):987-990. Available from: https://doi.org/10.1016/ j.jpowsour.2006.02.050.

16. Chen H, Luo H, Lan Y, Dong T, Hu B, Wang Y. Removal of tetracycline from aqueous solutions using polyvinylpyrrolidone (PVP-K30) modified nanoscale zero valent iron. J Hazard Mater. 2011;192(1):44-53. Available from: https://doi.org/10. 1016/j.jhazmat.2011.04.089.

17. Domenzain-Gonzalez J, Castro-Arellano JJ, Galicia-Luna LA, Lartundo-Rojas L. Photo-Fenton Degradation of RB5 Dye in Aqueous Solution Using Fe Supported on Mexican Natural Zeolite. Int J Photoenergy. 2019;2019:1-15. Available from: https://doi.org/10.1155/2019/4981631. 